Prolegómenos julio-diciembre - ISSN: 0121-182x · e-ISSN: 1909-7727 • pp. 53-67

\title{
Fiabilidad de la prueba testimonial: breve análisis desde la psicología del testimonio y los errores de la memoria*
}

\author{
Fernando Luna Salas ${ }^{a}$
}

\begin{abstract}
Resumen: este artículo de carácter jurídico e investigativo (investigación cualitativa con revisión bibliográfica) tiene como objetivo primordial describir y analizar los factores determinantes en la construcción de la memoria y de los recuerdos, con el fin de establecer el nivel de credibilidad y fiabilidad de la prueba testimonial.
\end{abstract}

Palabras clave: testigo; testimonio; errores de la memoria; psicología; fiabilidad; credibilidad

Recibido: 7 de abril de 2021 Aceptado: 21 de junio de 2021

Disponible en línea: 31 de diciembre 2021

Cómo citar: Luna Salas, F. (2021). Fiabilidad de la prueba testimonial: breve análisis desde la psicología del testimonio y los errores de la memoria. Prolegómenos, 24(48), 53-67. https://doi. org/10.18359/prole.5701

* El presente artículo de investigación surge de la investigación denominada "Fiabilidad de la prueba testimonial: breve análisis desde la psicología del testimonio y los errores de la memoria". El autor actuó en calidad de investigador principal y fue financiado por recursos propios dentro del Semillero de Investigación Ciencia y Proceso de la Facultad de Derecho de la Universidad de Cartagena, el cual está adscrito al grupo de investigación Filosofía del derecho, derecho internacional y problemas jurídicos contemporáneos de la misma Facultad.

a Magíster en Derecho de la Universidad de Cartagena y Especialista en Derecho Procesal de la Universidad Libre. Profesor Investigador de las cátedras de Derecho Procesal y Probatorio de la Universidad de Cartagena, Cartagena, Colombia. Director del Centro Internacional De Estudios Jurídicos y Políticos (CIEJP). Correo electrónicol: flunas@unicartagena.edu.co oRCID: https://orcid.org/0000-0003-4574-6335. 


\title{
Reliability of Testimonial Evidence: Brief Analysis from the Psychology of Testimony and Memory Errors
}

\begin{abstract}
: this legal research article (qualitative research with a literature review) intends to describe and discuss the determining factors in how memory works and memories are made to establish the level of credibility and reliability of testimonial evidence.
\end{abstract}

Keywords: witness; testimony; memory errors; psychology; reliability; credibility

Confiabilidade das provas testemunhais: breve análise da psicologia do testemunho e erros de memória

Resumo: este artigo de natureza jurídica e investigativa (pesquisa qualitativa com revisão bibliográfica) tem como objetivo principal descrever e analisar os fatores determinantes na construção da memória e lembranças, a fim de estabelecer o nível de credibilidade e confiabilidade das provas testemunhais.

Palavras-chave: testemunha; depoimento; erros de memória; psicologia; confiabilidade; credibilidade 


\section{Introducción}

A través de la historia la prueba testimonial ha sido clave en la resolución de los conflictos. Hasta la fecha ha sido una herramienta trascendental para llevar al juez a la convicción en relación con las proposiciones que se pretenden demostrar dentro de un proceso. De acuerdo con Nisimblat (2018), "el testimonio es la declaración que realiza un tercero, ajeno a la controversia, sobre algo que ha percibido, de manera directa, por cualquiera de sus cinco sentidos" (p. 371).

En la actualidad jurídica, y a pesar de los múltiples avances científicos y tecnológicos que vemos a diario, es extremadamente común encontrar procesos en donde el medio de prueba que prima es el testifical, aun en aquellos casos donde se puede considerar que la prueba reina debería ser una prueba pericial científica, sobre todo por la naturaleza del asunto que se trata.

De igual forma, resulta un lugar común en el imaginario colectivo de la mayoría de los juristas, y aun más de la sociedad en general, la errada idea o concepción de que, a partir de exteriorizaciones físicas o de señales indicativas de los testigos, se puede descubrir si está mintiendo o no; es decir, se cree fervientemente que cuando una persona está mintiendo actúa de manera extraña o con nerviosismo, de manera insegura, con mayor sudoración o una mayor gesticulación. También se puede pensar en sentido opuesto; que cuando una persona se expresa de manera segura, ese testimonio es verdadero o confiable. A la fecha, y con base en la psicología experimental, no existe un método fiable para descubrir cuándo un testigo miente, así como tampoco es dable afirmar que siempre una persona miente conscientemente o de manera predispuesta o intencionada. A pesar de lo anterior, y sin profundizar porque no es el resorte de este escrito, Luna (2019) plantea que, dentro de los estudios neurocientíficos aplicados al derecho, sobre todo a través de la técnica conocida como P300 o brainfingerprinting:

se puede demostrar, entre otras cosas, lo siguien-

te: por una parte, se puede establecer si una persona dice la verdad o no. Se trata de algo parecido al famoso detector de mentiras, pero su funcionamiento depende de técnicas neurocientíficas, en las que se controlan las variaciones de los flujos sanguíneos en el cerebro de la persona examinada. (p. 148)

A su vez, Contreras (2015) habla del análisis del comportamiento no verbal, así como de las microexpresiones faciales, y expresa:

que esta teoría sostiene que la mentira necesariamente provoca ciertas señales a nivel no verbal o paraverbal, que deben ser conocidas y correctamente interpretadas por el entrevistador, para de ese modo encontrar pistas de falsedad en el discurso del declarante. [...] Paul Ekman y sus colaboradores proponen que es posible detectar la mentira a partir de algunas expresiones faciales que pueden resultar visibles para quien posea el entrenamiento y los implementos audiovisuales adecuados. Esto se fundamenta en que la manifestación de cada una de las emociones se vincula a un movimiento determinado de ciertos músculos de la cara. (p. 248-251)

Sin embargo, se debe tener claro que ninguno de los intervinientes dentro de un proceso (así como ningún miembro policial o experto en interrogatorios ni el mismo juez por más años de experiencia) tiene la capacidad de identificar ni interpretar la gestualidad subjetiva de cada testigo en una audiencia y, sobre todo, en un espacio de tanto estrés y presión como ese. Afirmar lo contrario sería más bien una especie de ejercicio de adivinación, de quiromancia.

De acuerdo con múltiples estudios que más adelante se mencionarán, se ha concluido que una declaración testimonial nunca coincide o guarda relación fidedigna con lo acaecido en la realidad, es decir, existe una distorsión entre lo vivido o percibido y lo expresado en el testimonio, situación que tiene su génesis principalmente en el funcionamiento de nuestra memoria. A partir de estas afirmaciones es posible preguntarnos: ¿cuál es el grado de fiabilidad de un testigo?, ¿qué nivel de credibilidad o de confianza se le debe asignar a un testimonio?, ¿cómo hace un testigo para identificar a un presunto culpable después de varios meses o años?, ¿puede un testigo mentir sin ser consciente de ello?, ¿existe algún testimonio totalmente fiable? 


\section{Metodología.}

El presente trabajo intentará dar respuesta a los anteriores cuestionamientos a través del desarrollo de unas etapas conceptuales precisas, en el marco de un análisis de tipo jurídico, reflexivo y de carácter doctrinal. En este sentido, se considera importante que preliminarmente se ahonde en la memoria desde la óptica de la psicología del testimonio y la psicología experimental. Así mismo, se analizarán los distintos episodios que conllevan a que nuestros recuerdos se distorsionen o se reconstruyan de manera errada y, por ende, se desmitificarán concepciones arraigadas en la sociedad en cuanto al descubrimiento de la mentira, así como también, se intentará realizar aportes críticos que sirvan para un mejoramiento en la valoración judicial de la prueba testimonial.

El desarrollo conceptual que se acaba de describir será basado, desde el punto de vista de las fuentes, en una búsqueda y revisión bibliográfica que integra una metodología de investigación de tipo cualitativa. Particularmente, se considerarán los principales trabajos publicados sobre la materia en los últimos años en las principales revistas y libros de carácter científico.

\section{Marco Teórico.}

\section{a. La psicología del testimonio: antecedentes y definición.}

Desde el siglo xix se ha venido gestando una disciplina que nace a partir de la psicología: la psicología del testimonio, la cual ha pretendido dar ciertas luces al contexto judicial. Esta ciencia experimental pretende estudiar, conocer, entender y hasta predecir determinadas conductas humanas, se encarga de definir los factores que determinan la calidad o fiabilidad de un testimonio, así como su exactitud y credibilidad, al analizar los procesos internos de atención, percepción y memoria.

De igual forma, de la psicología del testimonio se puede extraer un conocimiento de vital importancia para los estrados judiciales, como fuera que este campo de la ciencia explica cómo se recuerdan los eventos, qué tan fiables son, dependiendo de la edad del testigo o de la clase de evento que se presenció y se intenta recordar, así como de la forma como se pretende recuperar la información. De acuerdo con Nieva (2010), los tres aspectos de la psicología del testimonio que más interesan al derecho son:

En primer lugar; la técnica de obtención de declaraciones, porque aporta una experiencia valiosísima basada en resultados corroborados, bien en estudios de campo, bien en la medida de lo posible en la práctica judicial. En segundo lugar, como decía, esta disciplina ayuda a detectar la mentira a través de aspectos objetivos. Y, en tercer lugar, la materia aporta una importante serie de datos a los efectos de practicar correctamente los reconocimientos de personas. (p. 215)

Dentro de la psicología del testimonio se encuentran dos grandes áreas estrechamente relacionadas, a saber, la exactitud y la credibilidad. Manzanero (2010a) explica que:

la primera trata de los estudios relativos a los factores atencionales, perceptivos y de memoria que influyen en la exactitud de las declaraciones y las identificaciones de los testigos presenciales. Varios temas han sido especialmente relevantes aquí: los procedimientos de obtención de las declaraciones (recuerdo, reconocimiento, entrevista cognitiva, ayudas al recuerdo...), los de identificación (fotografías, ruedas, retratos robot...), las diferencias individuales (edad, sexo, implicación, ansiedad...), la influencia de los procesos perceptivos en la interpretación de la información (percepción de sonidos, conversaciones, formas, velocidad, colores...), las falsas memorias (memorias recuperadas, información post-suceso, sugestibilidad...), el efecto de las condiciones atencionales en los procesos de codificación (efecto del arma, detalles sobresalientes, distintividad...), y otros factores de retención y recuperación (recuperación múltiple, efecto de las preguntas, preparación, demora...). La segunda área trata de la discriminación del origen de la información aportada por los testigos (perceptiva y real o sugerida, imaginada, falsa...). El abordaje de esta tarea se ha realizado desde la Psicología Cognitiva, 
tanto como desde la Psicología Social y la Psicología Clínica. Además, han resultado de interés las aproximaciones al estudio de la mentira desde la Neurociencia, la Psicofisiología, y la Psicología del Lenguaje y la Comunicación. (p. 89-90)

A modo de breves comentarios en torno a los antecedentes históricos generales del testimonio, se puede decir que existen referencias en textos griegos y romanos en relación con la importancia de los testimonios y la forma de obtener o llegar a la verdad. De igual forma, existen documentos de la época de la inquisición que expresan los tipos de testigos, su credibilidad o exactitud y directrices en cuanto a los interrogatorios, como es el caso del manual del inquisidor Directorium Inquisitorum publicado en 1376. Más adelante, en 1764, se publica el clásico De los delitos y las penas, del italiano Cesare Bonnesano, marqués de Beccaria, donde se explica sobre los testigos, interrogaciones sugestivas y declaraciones. Posteriormente, remontándonos a las primeras menciones,

"uno de los primeros escritos que específicamente habló de la Psicología del Testimonio fue el del francés A. Motet (1887), sobre los testimonios infantiles falsos, donde comentó casos reales desde el punto de vista de los problemas de sugestibilidad y distinción entre imaginación y realidad en los niños. Sin embargo, el hito más relevante en Europa fue la publicación de libro Kriminalpsychologie del austriaco H. Gross (1897), en gran parte dedicado al testimonio: exactitud, percepción, imaginación, memoria, y toma de declaración fueron algunos de los temas tratados. Ya en el siglo XX, nos encontramos con tres figuras fundamentales en el nacimiento de la Psicología del Testimonio desde un punto de vista experimental y aplicado al campo forense: Alfred Binet, Hugo Münsterberg y William Stern. Junto a Gross, los cuatro han sido considerados los co-fundadores de la especialidad". (Manzanero, 2010a, p. 90-91)

Como se puede evidenciar en las anotaciones anteriores, no es un tema novedoso o reciente, sino que por lo menos desde el campo psicológico se viene desarrollando desde hace ya varios años atrás y poco a poco ha ido ganando terreno en el campo jurídico. Esta situación es más que necesaria, toda vez que en la medida en que se le preste mayor atención, se evitará un mayor abuso, error o injusticia en las decisiones judiciales donde se termina condenando a inocentes; por ejemplo, cuando se basan exclusivamente en pruebas testimoniales y sin el menor rigor o control por parte del administrador de justicia en relación a los problemas que nos trae la psicología del testimonio. De acuerdo con De Paula Ramos (2019):

En 1996, el Instituto Nacional de Justicia estadounidense informaba de 28 condenas erróneas, revertidas con ayuda de prueba de ADN, y en cada una de ellas había al menos una identificación errónea: un total de 197 años de prisión injusta entre los 28 condenados.

En la actualidad, de los 347 casos de condenas revertidas registradas por el Innocence Project ${ }^{1}$, 240 están relacionadas con una identificación testifical equivocada, un porcentaje del 69,16 por 100 -número infinitamente mayor que el de cualquier otra causa, como la falsa confesión (97 casos), mala práctica (misconduct) del Estado (54 casos), defensa inadecuada (16 casos) o incluso prueba científica incorrecta (improper) o equivocada (157 casos)-. Es decir, "uno de los hechos más importantes que aprendemos con casos de exoneración que implican análisis de ADN es que los errores cometidos por testigos son el principal factor que contribuye a las condenas erróneas en Estados Unidos”. (p. 102)

\section{b. Memoria y testimonio.}

Al centrarnos en la fiabilidad y exactitud de un testimonio, necesariamente debemos ubicarnos en el contexto de la memoria del testigo. Ambos conceptos están estrechamente relacionados y ligados entre sí, siempre existirá una interacción de dependencia entre el contenido del testimonio, así como de los procesos internos decisorios de lo que pretende declarar o relatar y el contenido de la memoria.

1 En relación con la fundación "Innocence Project", podría consultarse más en: https://innocenceproject.org/all-cases/\#exonerated-by-dna 
Esa relación estrecha y de dependencia se puede evidenciar cuando, por ejemplo, un testigo recuerda con exactitud cada una de las circunstancias vividas y así las relata. Por el contrario, puede ocurrir que no recuerde nada o sus recuerdos son parciales, así como también puede existir la persona que, teniendo claridad sobre sus recuerdos, prefiere no decir nada o, de manera intencional, modificar sus recuerdos y declarar algo distinto. Y por último y bastante importante, puede existir el caso en que un testigo, obrando de buena fe, declare con lujo de detalles lo acaecido pero sin el más mínimo ápice de veracidad, es decir, es un testigo que relata lo que recuerda y, por ende, lo cree y considera como cierto o como verdad, pero en realidad es lo diametralmente opuesto, el testigo manifiesta recuerdos que están en su memoria pero que no son reales, o están distorsionados o modificados de manera no consciente. Este último caso sencillamente se puede resumir en que hay testigos que mienten, con la gran e interesante diferencia de que no son conscientes de ese actuar, no saben que están mintiendo. Todo lo anterior, y así lo explica la psicología del testimonio, tiene su razón de ser a partir de la naturaleza reconstructiva de la memoria, en donde la persona es honesta o sincera, pero para nada su testimonio cumple con ser veraz. Al respecto, Kate Germond (1998) explica que:

Muchas personas en nuestro país consideran la prueba testifical como la más profunda prueba de la verdad. "Este es el hombre que me hizo aquello". Todos asumimos, y con los años pasamos a creerlo, que nuestra mente es una grabadora, que simplemente graba de forma precisa cualquier cosa que vemos, oímos o con la que tenemos contacto. La verdad es que lo que nuestra memoria está en realidad grabando es, sí, lo que sucede en ese momento, pero también, mezclado con eso, recuerdos, sueños, algunas pequeñas distracciones: es un paquete de una gran variedad. Por tanto, nuestros recuerdos, en realidad, no son nada precisos.

Para desentrañar lo hasta aquí dicho, primero hay que plantear que cuando se habla de memoria hay que referirnos a nuestra capacidad, buena o pobre, de retener en la mente tanto las experiencias recientes como aquellas que constituyen nuestro pasado (Cofer, 1979). Desde la antigüedad se le ha otorgado a la memoria un papel trascendental en la vivencia humana y en la sociedad, desde Aristóteles en Grecia, así como Cicerón en Roma, y muchos otros con el transcurrir de los siglos se han preocupado por este elemento tan importante del intelecto humano, a tal punto que se han creado reglas y técnicas de memorización para un mejor desarrollo de la oratoria, como son la mnemotécnica o el método de los lugares.

La memoria en su actividad diaria está sujeta a distorsiones, es probable que un individuo recuerde eventos no verdaderos o que no han sucedido, es posible que recuerde situaciones en donde no ha tenido una experiencia directa, sino que sean experiencias ajenas que se incorporan como propias, o como producto de un mal interrogatorio se llegue a una sugestionabilidad, sobre todo tratándose de niños, todo esto gracias a que la memoria se considera como un acto creativo.

La información almacenada en nuestra memoria puede ser clasificada en tres tipos diferentes, dependiendo de la conciencia que la caracteriza. La información episódica es la responsable de nuestros recuerdos, nos hace conscientes de dónde y cuándo ocurrieron y con la experiencia subjetiva de haberlos vivido. La información semántica es la responsable de nuestros conocimientos, que sabemos que tenemos, pero no cuándo ni cómo los adquirimos. Por último, la información procedimental tiene que ver con nuestras habilidades, las cosas que sabemos hacer relativamente complejas y que hemos adquirido a través de la experiencia. (Manzanero, 2010, p. 30) A su vez, Nieva (2010), basándose en el anterior autor, plantea:

En el ámbito de la memoria a corto plazo, la capacidad para recordar estímulos auditivos es superior a la de los estímulos visuales. En ese mismo ámbito, se concluye que se recuerdan siempre mejor los primeros datos y los últimos de una lista, siendo más susceptibles de olvido los que se sitúan en medio del elenco.

Por su parte, en el ámbito de la memoria a largo plazo se distinguen dos tipos de memoria, la episódica, que es la autobiográfica, la referida a los 
recuerdos del individuo, y la memoria semántica, que es la que contiene los conocimientos que nos permiten interpretar cuanto vemos y, por supuesto, también nos permite valorar los datos de la memoria episódica. Pues bien, con respecto a esta última se distinguen tres procesos fundamentales: la codificación, que consiste en tomar la información percibida seleccionándola, dotándola de significado a través de la interpretación, y finalmente integrándola en las estructuras preexistentes de la propia memoria, formando lo que se llama la "huella de la memoria". En segundo lugar, hallamos la retención, que nos enseña que con el paso del tiempo tienden a deteriorarse las huellas de la memoria. Lo curioso es que la información también se recodifica con el tiempo, sobre todo cuando se viven acontecimientos similares $\mathrm{y}$ tienden a confundirse unos con otros, produciéndose falsos recuerdos. Y, en tercer lugar, tenemos el proceso más interesante a efectos procesales: el de recuperación, es decir; la búsqueda en nuestra memoria del recuerdo. El acierto en la búsqueda parece depender de que el individuo sea capaz de reinstaurar, en el momento de la declaración, la situación en que se produjo la codificación, es decir, que vuelvan a la memoria los elementos que sirvieron para almacenar la información. (p. 216)

En cuanto al funcionamiento de la memoria, Mazzoni (2010) explica:

El tipo de memoria más utilizado durante el testimonio es la memoria episódica, dado que los indicadores temporales y especiales que caracterizan los conocimientos contenidos en ella son indispensables para los fines de la instrucción. [...] el contenido de la memoria semántica, por la presencia de esquemas y scripts, incide también en el testimonio ya que interactúa con el contenido de la memoria episódica y, en algunos casos, hasta le da forma y contenido. La interacción entre memoria episódica y memoria semántica tiene lugar durante las tres fases principales de la memorización: durante la fase de adquisición de la información, llamada también fase de codificación, durante la fase en que la información es representada en la memoria, y en la fase de recuperación. La fase de codificación es una de las tres fases comprendidas en el más amplio proceso de recordar, y es en este nivel donde scripts y los esquemas pueden influir sobre el contenido de la memoria. [...] Nada puede ser recordado que no haya sido previamente codificado y después conservado en la memoria. (pp. 33, 34)

Como se ha dicho, el testimonio está estrechamente ligado en grado de dependencia a la memoria de la persona o del testigo, pues se conjugan dos elementos claves, la fiabilidad y la exactitud. La primera se refiere a la "correspondencia entre lo relatado y lo acontecido", mientras que el segundo elemento es "la correspondencia entre lo representado en la memoria y lo sucedido en el transcurso del hecho" (Mazzoni, 2010, p. 17).

La exactitud es, pues, lógicamente independiente de la cantidad de elementos recordados. Es decir, un recuerdo, incluso pobre, siempre que sea exacto, puede ser sumamente útil a los efectos de una investigación (Mazzoni, 2010, p. 18). Por ejemplo, los niños, en la medida en que se les permita relatar de manera espontánea sin ninguna clase de presiones o de cuestionamientos cerrados o de preguntas sugestivas o tendenciosas, serán capaces de recordar eventos pobres, sin mucha información, pero sí con mucha exactitud. En este caso es lo que se requiere para que el testimonio resulte altamente fiable. Así que, entre mayor margen de libertad exista en un interrogatorio a un niño, más espacio existirá para que el infante responda con mayor exactitud y, por ende, con mayor fiabilidad. En relación con las entrevistas realizadas a niños que han sido presuntamente víctimas de delitos sexuales, Köhnken, Manzanero y Scott (2015) consideran que otra fuente de declaraciones incorrectas no intencional son las falsas memorias. Estas pueden ser generadas por a) una reinterpretación errónea de hechos que tuvieron lugar, pero no responden a conductas de abuso sexual, b) inadecuados formatos de entrevista en el contexto de la investigación policial y judicial e c) inadecuados procedimientos terapéuticos. A su vez, Mazzoni (2010) en torno al punto anterior establece:

[...] Los recuerdos suelen ser tanto más exactos cuanto más afectan al elemento central del episodio objeto de investigación, y suelen ser más imprecisos en el 
caso en que el elemento, o los elementos importantes, sean periféricos en relación con la escena a la que ha asistido el testigo. [...] existe un fenómeno denominado "weapon effect", estudiado desde hace muchos años, según el cual, quien se ve amenazado por un arma de fuego tiene un recuerdo muy preciso del arma, pero no recuerda, sino de una manera muy vaga y poca precisa, otros elementos del episodio, como la persona que le apuntaba con el arma. El testimonio relativo al arma de fuego es completamente fiable pero el testimonio global relativo al episodio vivido es más bien casi inexistente y de escasa fiabilidad. (p. 19)

En torno al efecto de focalización en el arma, manifiesta De Paula Ramos (2019, p. 125) que no hay consenso sobre la explicación del citado efecto. Algunos creen que es una forma de autoprotección; en la medida en que las personas adultas saben que las armas pueden matar, centran la atención sobre el peligro, para evitarlo de forma instintiva. A pesar de lo anterior, se considera que lo más probable es que sea un efecto derivado de poner un objeto fuera de contexto (Loftus et al., 2013, pp. 33-34).

En cuanto a la fiabilidad del testimonio, se pueden hacer las siguientes apreciaciones:

- Con base en los estudios de la memoria, sobre todo en cuanto a sus límites, un testimonio en donde los recuerdos relatados son totalmente exactos y en detalle, muy seguramente es un testimonio que no debe gozar de un grado total de fiabilidad.

- La anterior afirmación en esencia se da porque es muy improbable que un individuo recuerde con lujo de detalles y de manera exacta todos los elementos integrantes de una escena.

- Es probable que, en el recuerdo relatado, existan circunstancias o elementos que no pertenecen a la escena vivida o presenciada, pero que de manera errada y sin intención fueron introducidos en la memoria. Este punto se podría ejemplificar con los denominados recuerdos colectivos, en donde un grupo de individuos que presenciaron un mismo hecho, al escuchar o interactuar con la versión segura del otro, puede modificar su recuerdo agregándole elementos nuevos a su memoria $\mathrm{y}$, por ende, a su testimonio.
- La fiabilidad del testimonio va a depender también de la edad del testigo, como bien se planteó anteriormente, un niño puede tener recuerdos muy exactos en la medida en que exista un interrogatorio bien direccionado, pero, a su vez, está demostrado que los niños son testigos menos fiables, toda vez que son personas con un alto grado de sugestionabilidad por parte de los adultos. "Los niños son vulnerables a las sugerencias de información falsa, más cuanta menor edad tengan, debido a la tendencia de los niños más pequeños a adaptarse a los deseos de los adultos" (Manzanero, 2010, p. 203).

- Otra circunstancia determinante en la exactitud de la memoria y, por ende, en la fiabilidad, es en relación al grado de atención o de conciencia que exista en el momento de presenciar el hecho, es decir, no es lo mismo como percibe un episodio un sujeto somnoliento a uno totalmente despierto, o como lo recibe una persona extenuada y cansada que uno relajado y descansado. De igual forma, sucede con personas en estado de excitación, ansiedad, emoción o preocupación.

- Un elemento adicional a considerar es la predisposición a recordar un hecho o, todo lo contrario, la falta de intención para recordar. Es decir, cuando un sujeto se programa o se predispone a que debe memorizar un episodio, después le será más fácil recordarlo. Sin embargo, se puede concluir que esto es algo que no ocurre frecuentemente, sobre todo con los hechos percibidos de manera espontánea.

- Otra apreciación que no se puede dejar pasar, y que desafortunadamente en nuestros sistemas judiciales la mayoría de veces juega en contra, es el factor tiempo, el lapso que se deja transcurrir entre el momento en que se percibe un hecho y el momento de la práctica del testimonio en audiencia.

- Otro factor importante "viene representado por los esquemas mentales de referencia que entran en juego al interpretar el significado del episodio. Ante cualquier situación tendemos a interpretar espontáneamente lo que está sucediendo, y lo que quede grabado en la memoria dependerá del modo en que el suceso venga interpretado." Es decir, "lo que queda en la memoria no es el objeto visto, sino el objeto interpretado" (Mazzoni, 2010, p. 20, 21) 
- En la mayoría de circunstancias se acostumbra a valorar un testimonio por el grado de confianza con que sea relatado, entre más seguridad se le imprima a una declaración, mayor grado de fiabilidad o validez se le dará, sin embargo, se insiste que considerar lo anterior es desconocer en muchas ocasiones que un testimonio que transmita seguridad y confianza no necesariamente cumple con ser un relato veraz. Así que todo aquel que valore y saque conclusiones a partir de lo anterior está basando su decisión en elementos meramente subjetivos y desconociendo lo que la doctrina ha denominado como errores sinceros en un testimonio.

Todo lo anterior invita a pensar e insistir que la exactitud de un testimonio resulta influida por distintos factores que conllevan a un recuerdo errado, entre ellos, se encuentran: las condiciones de codificación, de retención y de recuperación. Así pues, la memoria es producto de un acto creativo en donde, a pesar de lo que se cree, no tiene la capacidad de grabar, sino más bien de interpretar y reconstruir las experiencias vividas en la realidad. Y precisamente en esta reconstrucción está lo complejo del asunto, ya que en esta labor de reconstrucción de los recuerdos se encuentran dos tipos de errores de memoria, los de omisión y los de comisión. Al respecto, Manzanero (2010b) explica:

Los errores de omisión se dan cuando en lo que cuentan los testigos de un hecho faltan detalles importantes, por olvido o por ocultación; los errores de comisión son aquellos en los que los testigos introducen información falsa deliberadamente - mentirao debido a inducción autogenerada o generada por el efecto de información postsuceso, fallos en la distinción entre realidad y fantasía, inferencias erróneas...

Entre los factores de codificación se encuentran aquellos que afectan a los procesos perceptivos y de atención, y podemos dividirlos, a su vez, en factores del suceso y factores del testigo. (p. 23)

En cuanto a los factores del suceso, hacen referencia a los elementos que tienen mayor influencia en los testigos a la hora de codificar la información como, por ejemplo, los cambios de luz, la distancia, la percepción del color, del movimiento, la percepción auditiva o de objetos, la duración o tiempo de exposición, el dolor, la velocidad, la frecuencia y familiaridad, o la violencia que se presenció en los hechos. Cada una de estas circunstancias puede modificar el proceso de reconstrucción de un recuerdo. Imagínese un caso en relación con una ilusión perceptiva de un objeto, en donde nuestro sistema visual nos haga ver algo que no es, por ejemplo, un sujeto A observa a la distancia y en la oscuridad a un sujeto B, el cual tiene un objeto en sus manos, piénsese un celular que podría confundirse o percibirse como un arma de fuego. Otro ejemplo también puede ser los eventos donde están en juego los colores, pues está demostrado que cada color estimula de manera diferente el recuerdo. De Paula Ramos (2019, p. 119) consagra que "los colores son un código efectivo para organizar el mundo visual, un estudio reciente demuestra, mediante tres experimentos diferentes, que la "adherencia" (binding) de objetos rojos y amarillos es mayor que la de objetos verdes o azules".

De igual forma, puede suceder en el caso de la velocidad, donde "las estimaciones de velocidad tienen un grado de fiabilidad bajo" (De Paula Ramos, 2019, p. 121). Digamos que el sujeto X fue testigo de un accidente automovilístico y en su declaración él no puede manifestar cuantitativamente a qué velocidad iba el vehículo, simplemente podrá arrojar un estimado en cuanto a la velocidad de lo lento o rápido, a partir de elementos comparativos o asociativos, como la calle o la vía donde fue el accidente, así como del resto de vehículos que van circulando en ese instante. A su vez, en cuanto a la violencia o al tipo de suceso, se puede manifestar que, en la medida en que un testigo esté mayormente implicado en los hechos o tenga un mayor protagonismo en lo acaecido, más elementos emocionales estarán de por medio y, por consiguiente, existirá un grado mayor o más elevado en la distorsión de los recuerdos. Esto último lo desarrolla Clifford y Scott (1978) cuando explican que el testigo experimenta mayor estrés cuanta mayor violencia implica el suceso, y el estrés afecta negativamente a los procesos cognitivos como la atención, la percepción y la memoria. Junto con lo mencionado, se encuentra, además, la duración del suceso, "una exposición breve reduce la agudeza del testigo, cuanto más dure la exposición, mejor, 
en teoría, se recordará el suceso" (Heaton-Armstrong et al., 2006, p. 8).

Por otro lado, entre los factores de codificación tenemos los factores del testigo, en donde juega un papel primordial a la hora de interpretar lo sucedido, la individualidad de cada sujeto y sus experiencias vividas anteriormente. Dentro de estas variables se pueden encontrar la ansiedad, la edad, el sexo, los estereotipos, el alcohol o las drogas. Al hablar de los estereotipos, Manzanero (2010b, pp. 34-35) consagra que la memoria de los testigos está muy influida por los conocimientos y experiencias adquiridas antes y después del incidente. Cuando esperamos ver una determinada cosa, esté o no presente, es muy probable que nos parezca que la vemos. Los estereotipos son fruto normalmente de una exageración de alguna característica que presenta un colectivo. De igual forma, Mazzoni (2010) explica que "un estereotipo es una forma de juicio sobre un grupo de personas que elimina las diferencias entre los individuos pertenecientes al grupo y potencia los posibles elementos comunes. La presencia de estereotipos crea prejuicios, que son también formas de juicio que se formulan respecto de situaciones concretas antes de tener experiencia directa sobre ellas" (p. 45). Un ejemplo muy contundente que se puede mencionar de los estereotipos es el que está relacionado con la raza, el cual ha influido negativamente en los testimonios de múltiples casos que terminan condenando a inocentes, sobre todo en países como Estados Unidos.

En cuanto a la variable de la edad, cabe aclarar que cuando estamos frente a personas de avanzada edad, su memoria es menos precisa, la capacidad de recuerdo se va perdiendo, así como su capacidad perceptiva de la vista y el oído. Las personas mayores tienen mayor dificultad en cuanto al recuerdo de los detalles y el reconocimiento de personas. Fitzgerald y Price (2015), a partir del análisis de un experimento, consideran:

Los resultados que tienen un grado elevado de comprobación científica reflejan que los adultos jóvenes tienen más posibilidades de identificar personas que los adultos ancianos o los niños. Las posibilidades de acierto, en efecto fueron un $71 \%$ superior entre adultos jóvenes (entre 19 y 27 años) que, entre adultos de 45 a 77 años, y un 95\% cuando se reducía el conjunto de personas mayores a adultos entre 68 a 77 años. Con relación a los niños, se verificó un porcentaje del $42 \%$ superior en el caso de adultos jóvenes respecto a niños de 4 a 17 años.

Con relación a adultos jóvenes, tanto los niños como los adultos de más edad tuvieron una probabilidad menor de identificar correctamente al sospechoso y una probabilidad mayor de seleccionar a un falso sospechoso como tal. (pp. 1237, 1239, 1246)

A su vez, en torno al reconocimiento fotográfico y a la rueda de reconocimiento, reconocimiento en fila o lineup, consagrados dentro de nuestro ordenamiento en los artículos 252 y 253 de la Ley 906 de 2004, también existen ciertas apreciaciones a tener en cuenta. Mazzoni (2010, p. 23) señala que "nosotros, como individuos, creemos generalmente en la autoridad y, en consecuencia, cuando en una investigación, en este caso localizar al culpable, somos demandados por una persona autorizada y competente, nosotros lo hacemos [...] si la policía nos dice que el sospechoso está entre las fotos, creemos en la policía y no pensamos que vaya a engañarnos". De igual forma, Manzanero (2010, p. 180) explica que "las investigaciones sobre la memoria de los testigos nos indican que mostrar las fotografías al testigo podría estar viciando todo el posterior procedimiento de identificación, ya que en la rueda en vivo el testigo podría estar señalando a la persona de la fotografía y no al autor del delito. Por tanto, debemos valorar con mucha precaución las identificaciones hechas después de una exposición fotográfica”.

\section{Resultados.}

\section{c. Valoración de la prueba testimonial y propuestas formativas.}

"El juez debe oír al testigo con agrado y mansedumbre y mirándole a la cara, pues el semblante puede a veces conocer la sinceridad o la falsedad de su deposición". Vicente y Caravantes, 1856, p. 238 
Hasta este punto, se tienen múltiples elementos de juicio para replantear los esquemas mentales que se tienen en torno a la prueba testimonial, como es el caso de la cita anterior que, aunque es bastante antigua, aún sigue en la mente de un gran colectivo de juristas. Precisamente la psicología del testimonio nos invita a pensar no tanto en la valoración de aspectos conductuales del testigo, sino más bien en el análisis y la valoración detallada y coherente de la credibilidad del testimonio.

Lo anterior sería lo primero a tener en cuenta por parte de los administradores de justicia a la hora de valorar la prueba, quienes deben virar su mirada del mito y las falsas creencias a la ciencia experimental. De hacer lo contrario, se estaría frente a una valoración alejada de cualquier contexto crítico y objetivo. Como se mencionó en líneas anteriores, se estaría básicamente frente a actos adivinatorios que no resultan para nada bien, sobre todo, dentro de un contexto judicial. Recuérdese que, "al hablar de valoración de la prueba, se hace referencia a la labor del juez, dígase obligatoria, de realizar un análisis sobre el mérito de la convicción de la prueba" (Luna, 2018, p. 122) o, como dice Gascón, (2010), es un juicio de aceptabilidad de los resultados producidos por los medios de prueba.

Nótese que hay una variada información en relación con la memoria y el testimonio, información no tan sencilla de digerir porque es un conocimiento que se escapa de la cultura jurídica y que, además, choca con las creencias de muchos, pues que existen métodos mecánicos o intuitivos para detectar la mentira en una declaración. Nieva (2010) considera que existe una gran incidencia del heurístico de la representatividad entre los administradores de justicia, lo cual consiste en que "los jueces valoran en gran medida la actitud del declarante según lo que recuerdan de otros declarantes en casos anteriores que han juzgado" ( p. 221). De ahí que una de las finalidades de este trabajo sea entender grosso modo el funcionamiento de la memoria y, por ende, del testimonio, para poder aproximarnos a plantear una serie de herramientas o propuestas que sirvan a la comunidad jurídica en general, pero sobre todo a los jueces, en su labor crítica y racional de valoración probatoria, en concreto, de valorar la credibilidad del testimonio.
Para lograr el cometido anterior, cabe aclarar que "nunca se puede tener la certeza racional que una proposición es verdadera, lo que se puede conseguir dentro de un proceso y a través de los medios de prueba es que se le atribuya un específico grado de probabilidad o de confirmación de que un enunciado sea verdadero" (Luna, 2019, p. 57). En otras palabras, se está frente a un modelo de verdad por correspondencia, donde el juez no tiene que ser el centro de toda la actividad probatoria, ni deja de ser un administrador de justicia infalible, ni se busca una convicción subjetiva del juez que direccione la decisión, según su posición de qué tan convencido esté. Al contrario, lo que se pretende es que los conocimientos científicos sean relevantes y aporten a la búsqueda de la verdad de lo que realmente acaeció, pero desde una óptica meramente objetiva, analítica, crítica y racional. De lo contrario, estaríamos utilizando "en el derecho moderno ordalías disfrazadas de pruebas racionales" (De Paula Ramos, 2019, p. 142). Dicho lo anterior, se debe tener presente que el juez no puede, le queda imposible, realizar un filtro o depuración de los testigos a partir de creencias con un gran tinte mitológico, sin ningún asidero científico. Por ende, a continuación, se relacionarán algunas propuestas formativas con la intención de poder contribuir a una mejor administración de justicia, así como de aportar algunas luces en el mejoramiento del ejercicio judicial en un contexto general.

\section{d. Propuestas formativas.}

- Es importante iniciar con algo básico pero trascendental como el tema cultural, el tema educativo, sobre todo de los jueces: "hay que elevar su base cognoscitiva, brindarle formación y adiestramiento con el fin de que hagan con sentido este control crítico, el cual sin lugar a equívocos contribuye al mejoramiento de la administración de justicia" (Luna, 2018, p. 141). De igual forma, Haack (2020) considera lo siguiente: "parece que es tan factible como útil asegurarse de que los jueces entiendan las ideas científicas con las que es probable que se encuentren con mayor frecuencia: el rol de la sugestión, por ejemplo, y su 
importancia en cómo deben ser presentadas las muestras de ADN o las armas blancas que fueron supuestamente usadas, etc., o cómo desarrollar un reconocimiento fotográfico o una rueda de reconocimiento (p. 198).

- Aunado a lo anterior, es importante que los jueces, a partir del conocimiento y de los aportes brindados por la psicología experimental, den el salto a reevaluar sus posturas frente a la prueba testifical y emprendan un camino hacia la valoración objetiva y racional de este medio de prueba. Sobre todo, y como se mencionó anteriormente, se enfoquen, más que en la credibilidad del testigo, en la credibilidad de su testimonio. Es vital que la comunidad jurídica, y en especial los administradores de justicia, comprenda a partir de estos estudios la fragilidad de la prueba testimonial, sobre todo, por tener presente el sinnúmero de elementos que confluyen en el proceso de construcción de la memoria.

- Otro punto trascendental, y que se suma a los anteriores en cuanto al cambio de mentalidad, es que se debe comprender que un testimonio, "no por el hecho de ser falso, por no ajustarse a la realidad de lo ocurrido, no deja de ser sincero en cuanto a lo que el testigo cree por cierto y pudo extraer de su memoria”. Razón tiene De Paula Ramos (2019, p. 143) cuando menciona que no se puede simplemente presumir que un testimonio sin pruebas en contrario es verdadero. Este mismo autor a renglón seguido expresa una afirmación completamente cierta: "sin pruebas que confirmen el testimonio de un sujeto, no se puede decir nada sobre su sinceridad y, menos aún, sobre su veracidad. Puesto que para el proceso la verdad es extremadamente importante, el derecho no puede presumir sin más la veracidad de un testimonio, con lo que se trata de una forma muy poco fiable por sí sola de obtener conocimientos" (De Paula Ramos, 2019, p. 143).

- De acuerdo con lo expresado, se tiene claridad de que la prueba testimonial es muy débil y, por consiguiente, tiene un grado de fiabilidad muy bajo. Esto conlleva a pensar que este medio de prueba por sí sola resulta insuficiente, sobre todo para el cometido esencial del proceso. Por ende, resultaría acertado que el juez pudiera corroborar el testimonio con otros medios de prueba.

- Se deben tener muy presente los errores que pueden ocurrir en la construcción de la memoria, del recuerdo y, desde luego, en la declaración. Los jueces deben tener las herramientas formativas para poder distinguir que no todo testigo que miente lo hace conscientemente, que existen errores sinceros en los testimonios, los cuales producen que un testigo declare de manera mentirosa pero verdadera. Precisamente, esta sería una de las principales razones para pensar lo planteado en el punto anterior, es decir, la corroboración con otros medios de prueba.

- Existe un trato incorrecto hacia los testigos, trato no solo por parte de los sujetos procesales, sino también por parte de la policía judicial, es decir, del conjunto de servidores públicos o de autoridades que contribuyen con la investigación de los delitos. Al hablar de trato incorrecto, en esencia se hace referencia a la forma de cómo se interroga a los testigos, de la clase de preguntas que se les realiza y de lo que en muchas ocasiones se les transmite a través de meta mensajes, ya sea de manera consciente o inconsciente. Varendonck, citado por Mazzoni (2010), considera que "una pregunta mal formulada puede conducir a dar respuestas completamente erradas, incluso tratándose de personas que un niño ve todos los días" (p. 81). A su vez, esta misma autora considera que sucede con demasiada frecuencia "ver en las entrevistas que quien las conduce formula las preguntas como si ya supiese de un modo cierto cómo habían sucedido las cosas y pidiese simplemente al individuo que confirmara algo ya conocido" (p. 82).

- En cuanto a la forma inadecuada de interrogar, la psicología experimental nos enseña que es recomendable utilizar una técnica narrativa en las interrogaciones, es decir, que las preguntas sean abiertas para permitirle al testigo su declaración de los hechos de manera libre y espontánea, sin ninguna clase de interrupciones, excepto para direccionar la declaración o para preguntar algo en concreto que se desprenda de su testimonio, sobre todo para evitar los denominados errores 
de omisión. Estos errores en esta forma de interrogatorio son muy comunes por la falta de detalle y precisión, es decir, la forma narrativa se caracteriza por relatos generales de lo acaecido. La diferencia entre interrogar con preguntas abiertas a través de la técnica narrativa y la técnica interrogativa, se centra en que esta última puede propiciar en el testigo lo que en líneas anteriores se mencionó como errores de comisión, pues a través de la pregunta el interrogador puede estar introduciéndole al declarante información que conlleve a la distorsión de su memoria y, por ende, a falsos recuerdos.

Manzanero (2010) considera que el formato interrogativo tiene la ventaja de proporcionar una gran cantidad de información, pero con más distorsiones que las aparecidas en el formato narrativo. Esta característica de más detalle, pero menos exactos, se debe al efecto que las preguntas tienen sobre la memoria. Así que se reitera que "la mejor técnica de interrogatorio es la de, antes de cualquier pregunta, permitir que el testigo exponga libremente lo hechos, pues las versiones y las respuestas dadas en esta fase son más fiables que las ofrecidas a preguntas directas" (De Paula Ramos, 2019, p. 160). Así mismo, Diges (2016, p. 39) considera que la mejor fórmula es iniciar la declaración con una petición general, en términos de recuerdo libre ("cuénteme lo que pasó"), acentuando la idea de que interesa un relato detallado y procurando no interrumpir.

- Se deben buscar métodos que propendan por el cuidado y el aseguramiento de la memoria del testigo. En este orden de ideas, es muy común que, dentro de una investigación penal, por ejemplo, se interrogue en múltiples ocasiones a la víctima. Está demostrado que la calidad y exactitud de los recuerdos se ve distorsionada por la cantidad de veces que el individuo debe realizar la recuperación de un suceso en su memoria. Alba y Hasher, citado por Manzanero (2010, p. 49), consideran que el hecho de que hayan vivido una situación atípica suele implicar que piensen con frecuencia en lo sucedido, y cada vez que se recuerde el suceso, la huella de la memoria que lo representa se reconstruye, lo que implica que con cada recuperación los recuerdos se van transformando mediante la incorporación de nuevos datos y la reinterpretación de los ya existentes.

- Se puede encontrar también a testigos con imposibilidad de recordar lo vivido, situación aun más grave si lo que se pretende es la reiteración de interrogatorios, como se mencionó en el punto anterior. Sin embargo, existe como procedimiento recomendable en la recuperación de los recuerdos, y como mejor alternativa contra las desventajas del formato narrativo e interrogativo, la denominada entrevista cognitiva. A través de esta entrevista, pese a sus detractores y críticos, se pretende evitar los errores de omisión y comisión en la recuperación del recuerdo y, según Memon y Koehnken (citado por Manzanero, 2010, pp. 5456), la entrevista cognitiva comprende tres procedimientos: primero, crear un ambiente propicio; segundo, recuerdo libre y, tercero, aplicación de técnicas específicas de recuperación de memoria donde se puede encontrar la reinstauración cognitiva del contexto, la focalización del recuerdo y la recuperación extensiva.

- A partir de los puntos anteriores, se podría llegar a dos recomendaciones. La primera, que sería favorable sobre todo para evitar contaminaciones en la memoria, que a los testigos se les tomara declaración de manera inmediata una vez haya ocurrido el episodio vivido, obviamente garantizando un debido proceso durante la entrevista, la cual, sí o sí, deberá ser grabada. La segunda recomendación va dirigida a la idoneidad de la persona quien pregunta. Por tanto, a partir de los datos arrojados por la psicología del testimonio, se requiere la experticia correcta para direccionar de la mejor manera la declaración de un testigo, situación que conlleva a plantear que se requiere mejor preparación y formación científica de los jueces, abogados y demás intervinientes dentro de una investigación. Así mismo, nos plantea de la necesidad de la presencia obligatoria de un experto en la materia que sea quien filtre y depure las preguntas en un juicio, por ejemplo, y se las replantee al testigo, es decir, que todos aquellos interrogatorios dentro de un contexto judicial se hagan con la presencia de personal capacitado e 
idóneo para estos menesteres, pues es el encargado de preguntar al testigo a partir de la pregunta inicial que realice la parte interesada o hasta el mismo juez. De ahí que se afirme que "la peor persona posible para llevar a cabo el interrogatorio es el abogado, puesto que el trabajo del abogado es justamente influir en el testigo dentro de la legalidad, usando todas las técnicas posibles permitidas para hacer que el testigo diga lo que favorece su versión de los hechos" (De Paula Ramos, 2019, p. 163).

- Desde la óptica del testigo, lo ideal sería que apenas una persona presencie unos hechos que podrían servir posteriormente en un proceso, no dialogue con nadie más en relación con lo presenciado y que, además, escriba sus recuerdos; de esas dos maneras podríamos aminorar el riesgo de distorsión de la memoria con el pasar del tiempo, o por los llamados recuerdos colectivos.

- Otro punto importante, y que tiene que ver con los peritos a la hora de entrevistar a una persona que, por ejemplo, ha sido víctima de algún delito de índole sexual, es también su idoneidad. Se requiere primero que los expertos estén debidamente formados en estos conocimientos y en las técnicas adecuadas y pertinentes que la misma psicología experimental consagra y, a su vez, como punto de suma trascendencia, se requiere que los peritos no lleguen a conclusiones a partir de sesgos de confirmación. Al respecto, Köhnken, Manzanero y Scott (2015) explican:

Uno de los componentes más importantes, y de hecho crucial, del sva es el planteamiento riguroso de hipótesis, es decir, el análisis sobre todas las fuentes potenciales u orígenes de la declaración. Todo lo demás, el procedimiento de evaluación, los datos que deben recogerse y las estrategias de evaluación específicas dependen finalmente de la formulación de estas hipótesis. Es perentorio que la persona que realiza la evaluación no tenga especial empeño en "descubrir" abusos sexuales, sino que debe ser lo más neutral posible y abierta a que los hechos invocados puedan haber sucedido o no. De lo contrario, fácilmente podrá caer en el error del sesgo confirmatorio, esto es, que tratando de confirmar una hipótesis se tienda a valorar más positivamente aquellos elementos que la confirmarían, pasando desapercibidos las declaraciones o circunstancias que la negarían. (p. 3)

El Statement Validity Assessment o el análisis de la validez de las declaraciones es uno de los procedimientos más empleados para analizar la credibilidad de un testimonio. "El sva es un procedimiento comprehensivo para generar y probar hipótesis sobre las posibles causas de las declaraciones incorrectas, así como para detectar el origen de una declaración determinada" (Köhnken et al, 2015, p. 3). Se explica que "es un método que requiere una notable destreza y parece útil para identificar afirmaciones verdaderas, en el $80 \%$ de los casos, y afirmaciones falsas, en el 65\%" (Mazzoni, 2010, p. 140).

\section{Conclusiones.}

No es la intención de este trabajo sentar cátedra en relación con temas de psicología, ni más faltaba, sobre todo por dos razones principales: la primera, el que escribe no tiene las competencias formativas ni la idoneidad para ello y, segundo, como se ha podido evidenciar, los temas aquí tratados desde la óptica de la psicología del testimonio vienen de muchos años atrás y están planteados por personas extremadamente capacitadas y formadas íntegramente en estos cauces de la mente. Sin embargo, sí se hace menester que la comunidad jurídica conozca y se percate, aunque tarde, de los intríngulis de la memoria, que se comprenda que los testigos cuando declaran a partir de sus falsas memorias no necesariamente están mintiendo de manera consciente, sino, por el contrario, lo hacen con la certeza y tranquilidad de que sus recuerdos son reales y ajustados a lo que ellos percibieron de los hechos. De igual forma, es indispensable que la administración de justicia, así como cada sujeto que sirve de eslabón en un proceso o investigación judicial, entienda que en muchas ocasiones se está contribuyendo negativamente con su actuar a crear los llamados errores sinceros, se está apoyando con su forma de preguntar o de tratar al testigo a que este distorsione su recuerdo y, por 
ende, se perjudique la exactitud y fiabilidad de su testimonio. De acuerdo con Contreras (2015), ninguna técnica de estimación de credibilidad podrá considerarse - ni aspirar a ser- el método infalible de control de la mentira, pues por el momento dicha conquista escapa a las capacidades humanas. A partir de lo anterior, es vital que se tome conciencia de lo frágil que puede llegar a ser la prueba testimonial y, por ende, se tomen lo correctivos necesarios y se apliquen las medidas formativas pertinentes para un mejor desarrollo y materialización de la administración de justicia.

\section{Bibliografía}

Cofer, C. H. (1979). Estructura de la memoria humana. Barcelona: Ediciones Omega.

Contreras Rojas, C. (2015). La valoración de la prueba de interrogatorio. Madrid: Marcial Pons.

Congreso de la República de Colombia (2004, 1 de septiembre). Ley 906 de 2004. Código de Procedimiento Penal Colombiano. Diario oficial n. ${ }^{\circ} 45.658$.

Clifford, B. R., y Scott, J. (1978). Individual and situational factors in eyewitness testimony. Journal of Applied Psychology, 63(3), 352-359. https://doi.org/10.1037/00219010.63.3.352

De Paula Ramos, V. (2019). La prueba testifical. Del subjetivismo al objetivismo, del aislamiento científico al diálogo con la psicología y epistemología. Madrid: Marcial Pons.

Diges, M. (2016). Testigos sospechosos y recuerdos falsos. Estudios de psicología forense, Madrid: Trotta.

Gascón, M. (2010). Los hechos en el derecho. Bases argumentales de la prueba. 3ra ed. Madrid: Marcial Pons.

Köhnken, G., Manzanero, A. y Scott, M. T. (2015). Análisis de la validez de las declaraciones: mitos y limitaciones. Anuario de Psicología Jurídica. http://dx.doi. org/10.1016/j.apj.2015.01.004

Haack, S. (2020). Filosofía del derecho y de la prueba. Perspectivas pragmáticas. Madrid: Marcial Pons.

Vicente y Caravantes, J. (1856). Tratado histórico, crítico filosófico de los procedimientos judiciales en materia civil según la nueva Ley de enjuiciamiento, Madrid: Impr. de Gaspar y Roig editores.

Fitzgerald, R. J., y Price, H. L. (2015). Eyewitness identification across the life span: A meta-analysis of age differences. Psychological Bulletin, 141(6), 12281265. https://doi.org/10.1037/bul0000013
Medstar Television (1998, 3 de diciembre). Crime Seen (temporada 3, episodio 10) en Forensic Files.

Heaton-Armstrong, A., Shepherd, E., Gudjonsson, G., y Wolchover, D. (2006). Witness Testimony. Psychological, investigative and Evidential Perspective, New York: Oxford University Press.

Loftus, Elizabeth; Doyle, James M., y Dysart, Jennifer E. (2013). Eyewitness testimony. Civil and Criminal, 5a . ed., San Francisco: Lexis Nexis.

Luna Salas F. (2019). Técnicas neurocientíficas como medio de prueba pericial. Revista Prolegómenos, 22(44), pp. 143-154. https://doi.org/10.18359/prole.4160

Luna Salas, F. (2019). Hechos, Verdad y Prueba. En F. Luna y E. de Río. Compendio de Derecho Probatorio Contemporáneo, p. 39-59. Bogotá, Colombia: Grupo Editorial Ibáñez.

Luna Salas, F. (2018). El mito del cientificismo en la valoración de la prueba científica. JURÍDICAS CUC, vol. 14, no. 1, pp. 119-144. http://dx.doi.org/10.17981/juridcuc.14.1.2018.6

Manzanero, A. (2010a). Hitos de la historia de la psicología del testimonio en la escena internacional. Boletín de Psicología, No. 100, pp. 89-104. https://www.uv.es/ seoane/boletin/previos/N100-6.pdf

Manzanero, A. (2010b). Memoria de testigos. Obtención y valoración de la prueba testifical. España: ediciones Pirámide.

Mazzoni, G. 2010. ¿Se puede creer a un testigo? El testimonio y las trampas de la memoria. Madrid: Editorial Trotta.

Nisimblat, Nattan (2018). Derecho probatorio. Técnicas de juicio oral. Ediciones Doctrina y Ley.

Nieva Fenoll, J.i (2010). La valoración de la prueba. Madrid: Marcial Pons.

Sheperd, J. W., Ellis, H. y Davies, G. M. (1982). Identification evidence. A psychological evaluation. Aberdeen: Aberdeen University Press. 